\title{
NOVEDADES SOBRE INCONSTITUCIONALIDAD POR OMISIÓN: LA CORTE CONSTITUCIONAL DE ECUADOR COMO LEGISLADOR SUPLENTE Y PRECARIO ${ }^{1}$
}

\section{Latest on unconstitutionality by omission: Constitucional Court of alternate and Ecuador as legislator precarious}

\author{
Néstor Pedro Sagüés ${ }^{2}$ \\ Profesor Titular de Derecho Constitucional, \\ Universidades de Buenos Aires y Católica Argentina \\ nestorsagues@arnet,com.ar \\ nsagues@ucaderecho.org.ar
}

RESUMEN: El autor analiza dentro de las nuevas competencias del Tribunal Constitucional Ecuatoriano, la inconstitucionalidad por omisión en perspectiva comparativa con otros países de América Latina, como asimismo el carácter de legislador precario que le otorga la Constitución al Tribunal Constitucional, mientras el legislador no cumpla su tarea de regular la materia respectiva, analizando críticamente dicha perspectiva.

PALABRAS CLAVE: Tribunal constitucional; inconstitucionalidad por omisión; Tribunal Constitucional como legislador precario.

ABSTRACT: The author analyzes the new powers within the Constitutional Court of Ecuador, the unconstitutionality by omission in comparative perspective with other Latin American countries, as also the precarious nature of legislature that gives the Constitution the Constitutional Court, while not fulfill its task legislator to regulate the subject matter concerned, critically analyze that perspective.

KEY WORDS: Constitutional Court; unconstitutionality by omission, the Constitutional Court as a legislator precarious.

1 El presente trabajo se inserta dentro del programa de investigaciones del Centro Interdisciplinario de Derecho Procesal Constitucional, de la Facultad de Derecho y Ciencias Sociales del Rosario, de la Universidad Católica Argentina.

2 Doctor en Derecho por la Universidad de Madrid. Profesor Titular de Derecho Constitucional de las Universidades de Buenos Aires y Católica Argentina. Presidente del Instituto Iberoamericano de Derecho Procesal Constitucional. Ex Presidente de la Asociación Argentina de Derecho Constitucional. Artículo enviado el 15 de junio de 2009. Aprobado el 23 de septiembre de 2009. 
La nueva Constitución del Ecuador, aprobada por referéndum el 28 de septiembre de 2008, ha remodelado con cierta intensidad al antiguo Tribunal Constitucional que existía en tal país, que con distintos nombres y competencias, es uno de los más antiguos de América Latina. En términos generales, ha reforzado sus roles y aumentado su autonomía. ${ }^{3}$

Nos interesa detenernos en un aspecto de la reforma constitucional, como es el concerniente a la inconstitucionalidad por omisión. El actual inciso $10 \mathrm{del}$ art. $436 \mathrm{de}$ la Constitución se detiene específicamente en el tema y dispone lo siguiente, entre las competencias de la nueva y ahora denominada Corte Constitucional: Declarar la inconstitucionalidad en que incurran las instituciones del Estado o autoridades públicas que por omisión inobserven, en forma total o parcial, los mandatos contenidos en normas constitucionales, dentro del plazo establecido en la Constitución o en el plazo considerado razonable por la Corte Constitucional. Si transcurrido el plazo la omisión persiste, la Corte, de manera provisional, expedirá la norma o ejecutará el acto omitido, de acuerdo con la ley.

Como puede constatarse, de haber una intimación por parte de la Corte Constitucional para que el órgano renuente se expida, la cláusula habilita a la misma Corte para que, de manera provisional, emita la norma ausente o ejecute el acto omitido, de conformidad con la ley.

La norma de referencia guarda similitud con la sancionada para el Estado de Chiapas (México), por decreto publicado en el periódico oficial del 16 de mayo de 2007, ${ }^{4}$ según la cual, cuando se considere que el Congreso no ha resuelto alguna ley o decreto y que dicha omisión afecte al debido cumplimiento de la Constitución, el Tribunal Constitucional del Estado intimará al Congreso para que resuelva la omisión en un período de sesiones, y si no lo hace, cuando se trate de leyes cuya expedición está ordenada por la Constitución local o federal, el referido Tribunal Constitucional se pronuncia en torno a la omisión, emitiendo provisionalmente las disposiciones pertinen-

3 La nueva Constitución declara a la Corte Constitucional como el máximo órgano de control de la constitución (art. 429). Se integra con nueve miembros, que duran nueve años sin reelección inmediata (art. 432), período felizmente ampliado con relación al corto tramo anterior de cuatro años. No están sometidos a juicio político. No pueden ser removidos por quienes los nombraron. En caso de responsabilidad penal son enjuiciados por la Corte Suprema de Justicia. Su destitución se decide por los tercios de los miembros de la Corte Constitucional (art. 431). Sus miembros son designados por una Comisión Calificadora de seis miembros (dos designados por la función legislativa, dos por la ejecutiva y dos por la de Transparencia y Control social), mediante concurso público: art. 435. La función de Transparencia y Control social se forma por el Consejo de Participación Ciudadana y Control Social, la Defensoría del Pueblo, la Contraloría General del Estado y las superintendencias (art. 204). En la práctica, habrá que analizar en el futuro si la Comisión Calificadora concluye o no efectivamente libre de influencias de los otros poderes del Estado. La autonomía funcional de la Comisión será un dato indispensable para erigir una Corte Constitucional a su vez imparcial e independiente.

4 Cfr. Rangel Hernández, Laura Maribel. (2008). Inconstitucionalidad por omisión legislativa en México (México, D.F.). Tesis para optar por el grado de Maestro en Derecho Procesal Constitucional. Universidad Panamericana, pp. 157/8, versión policopiada, a quien seguimos en esta descripción. 
tes, añadiéndose "que dicha legislación estará vigente hasta que el Congreso subsane la omisión legislativa” (art. 56, fracción III de la Constitución del Estado).

No preocupa mayormente que un órgano de la jurisdicción constitucional, ante un caso de omisión inconstitucional, ordene cumplir un acto concreto omitido. Esto es frecuente en el derecho procesal constitucional, y para ello existen, habitualmente, acciones de amparo o mandamientos de ejecución. Pero lo que sí llama la atención es la habilitación constitucional para que, ante supuestos de omisión inconstitucional en la producción de normas generales, el referido tribunal pronuncie -bien que provisionalmente- a la regla jurídica ausente.

En definitiva, la Constitución programa a la Corte Constitucional como un legislador suplente y precario, problemática en la que nos vamos a detener.

\section{ANTECEDENTES}

Hay múltiples remedios jurisprudenciales y constitucionales para atacar a la inconstitucionalidad por omisión. Baste mencionar, al respecto, sistemas que contemplan una denuncia ante el órgano que controla tal omisión, y otros que pueden proseguir con recomendaciones, llamados de atención o intimaciones al órgano en mora, la cobertura judicial para un caso concreto, la imposición de un resarcimiento por el daño causado, etc. Nos remitimos al tratamiento que hemos dado a ellos, en trabajos anteriores. ${ }^{5}$

Con referencia específica a la actuación de una Sala o Tribunal Constitucional como legislador suplente, y sin pretender agotar la temática, es posible citar a la Constitución de Venezuela de 1999, que en su art. 336 inc. $7^{\circ}$, al contemplar la inconstitucionalidad por omisión en la generación de normas por parte del poder legislativo nacional, estadal o municipal, establece que la Sala Constitucional del Tribunal Supremo de Justicia "establecerá el plazo y, de ser necesario, los lineamientos de su corrección". Aquí ya se anticipa una gestión como legisladora positiva de la Sala Constitucional, respecto del posible contenido que deberá tener la futura norma a dictarse.

Merece igualmente recordarse el caso de la constitución del Estado mexicano de Veracruz, y con alusión a la mora legislativa inconstitucional del Congreso, cuando estatuye que el Tribunal Superior de Justicia fija un plazo de dos períodos ordinarios de sesiones, para que elabore a la norma faltante; y si "transcurrido este plazo no se atendiere la resolución, el Tribunal Superior de Justicia dictará las bases a que deban sujetarse las autoridades, en tanto se expide dicha ley o decreto".

En esta hipótesis, el perfil del Tribunal Superior de Justicia como legislador suplente tiende a definirse más. Se trata de su aptitud constitucional para "dictar las bases"

5 SAGüés, Néstor Pedro. (2006) La interpretación judicial de la Constitución, $2^{\mathrm{a}}$ Ed. (Buenos Aires, ed. LexisNexis), pp. 129 y siguientes, cap. X: "Los jueces y la inconstitucionalidad por omisión”. 
(hecho que implica emitir normas, bien que no todas las reglas del caso) que regularán el tema hasta tanto lo haga el legislador ordinario. Para Fernández Rodríguez, está potenciado para emitir "una especie de normativa básica”. ${ }^{\circ}$

Pero en el caso ecuatoriano, aproximándose a la alternativa seguida en Chiapas, tal definición es todavía más categórica, ya que, como vimos, consiste en que la Corte Constitucional "expedirá" la norma ausente, bien que de manera "provisional”, y conforme a la ley.

\section{FUNDAMENTOS DE LA SOLUCIÓN CONSTITUCIONAL}

Es notorio que en la receta ecuatoriana prevalece la intención de afirmar la fuerza normativa de la Constitución, entendida como regla motorizable por la Corte Constitucional, cuando la inacción del legislador regular del caso (que puede ser no solamente el Poder Legislativo formal, sino toda otra autoridad que debe, según la Constitución, pronunciar una norma), paraliza su eficacia. Esa suerte de anestesia inconstitucional de la Constitución, por la renuencia del legislador moroso, es salvada así, de modo subsidiario y provisional, por la Corte Constitucional.

Acompañando ese razonamiento, es visible asimismo que la Constitución ha querido que la vigencia de los derechos enunciados por ella no quede a la merced de la voluntad del órgano normalmente emisor de normas, de sancionarlas o no sancionarlas. La solución, por cierto drástica, ha sido dejar a la magistratura constitucional (en su máximo nivel) la cobertura transitoria de la norma faltante. Para ello, la Constitución "judicializa" el conflicto (que décadas atrás era una political question, o cuestión política no justiciable), y lo inserta dentro de las competencias de la Corte Constitucional.

Por supuesto, la primera crítica a este régimen es la hipotética violación al principio de división de poderes, dado que la Corte Constitucional estaría cumpliendo aquí funciones nomogenéticas encargadas por la Constitución, inicialmente, a otros órganos. Vale la pena observar que se trata aquí de una impugnación de tipo académico y conceptual, ya que no es una violación de la Constitución, desde el momento en que es la misma carta política la que programa al sistema que analizamos.

Liminarmente cabe alertar que el órgano presuntamente "invadido" mal podría considerarse "víctima", ya que si hubiese emitido la norma que no dictó, no existiría problema alguno. Nadie puede, según el viejo adagio latino, alegar su propia torpeza.

6 Fernández Rodríguez, José Julio. (2003). "La omisión legislativa en la Constitución del Estado de Veracruz. Llave en el marco de la teoría general del dicho instituto", en Ferrer Mac Gregor Eduardo (Coord.), Derecho Procesal Constitucional, $4^{\text {a }}$ ed., (México, Ed. Porrúa), t. IV, p. 3771, quien critica profundamente la alternativa seguida por la constitución veracruzana, por afectar el principio de división de los poderes. 
Además, cada cual es responsable de sus propios actos (en la especie, de su propia omisión, infractora de la constitución).

Al mismo tiempo, el citado órgano hipotéticamente "invadido" podría concluir inmediatamente, si lo quisiera, con la supuesta "invasión" de la Corte Constitucional. Como ésta actúa aquí "de manera provisional” -o sea, como legislador precario-, si el órgano constitucionalmente previsto que no sancionó la norma, lo hace cumpliendo con su deber constitucional, ipso jure concluye la norma dictada por la Corte Constitucional. Las normas elaboradas por la Corte son, en definitiva, preceptos bajo condición resolutoria (sub conditionem resoluitur): tienen vigencia hasta tanto el legislador normal quiera mantenerlos, ya que puede sustituirlos con la norma que él desee sancionar, cumpliendo con el mandato constitucional que le obliga a aprobarla.

En conclusión, no parece haber aquí ni “órgano invadido”, ni “órgano víctima”.

\section{CRIITICAS}

El cuestionamiento más fuerte a la doctrina de la Corte Constitucional como legislador suplente y precario viene por otros lados. Mencionaremos tres argumentos: a) el técnico; b) el político; c) el funcional.

\section{a) El argumento técnico}

El mismo apunta que dictar sentencias (objetivo primario de un tribunal constitucional) no es lo mismo que elaborar normas generales (meta del legislador).

La preparación y redacción de una norma cuenta con técnicas específicas, bastantes exigentes por cierto, ${ }^{7}$ que en la esfera académica han dado lugar, incluso, a maestrías especializadas, como la actualmente en curso en la Universidad de Buenos Aires. Por lo demás, requiere oficinas de información y de asesoramiento, con personal especializado y un material informativo puesto al día, en temas muchas veces complejos.

El dictado de una norma general exige igualmente empalmar el nuevo texto con las normas afines, circunstancia que obliga a tener muy en cuenta normas preexistentes, o modificarlas. De no tomarse esas precauciones, el principio de derogación tácita orgánica (lex posterior derogat priori) puede provocar abrogaciones no queridas por quien está operando como legislador, o desajustes normativos muy perniciosos para la seguridad jurídica.

Con esto quiere significarse el arte y la ciencia de legislar no es un trabajo para amateurs, y que una corte constitucional que quiera operar como legislador, aunque

7 Ver Muñoz Quesada, Hugo Alfonso y HabA, Enrique Pedro. 1996. Elementos de técnica legislativa (San José de Costa Rica, Ed. Prodel). 
precario y suplente, puede no ser el órgano más adecuado para estas nuevas funciones, que en principio resultan anómalas para el tribunal. De todos modos, si las asume, ello requeriría cuerpos especializados dentro de la corte, para coadyuvar con eficiencia en dicho trabajo.

\section{b) El argumento político}

Desde este punto de observación cabe añadir que el oficio de legislar es políticamente muy significativo (principalem actus regis, lo llamaba Santo Tomás de Aquino), ${ }^{8}$ y que, en un Estado democrático, requiere deliberación, confrontación de posiciones, demandas colectivas e ideologías, elaboración de fórmulas conciliatorias y transaccionales entre los diferentes grupos políticos que conforman la sociedad, y a menudo, adoptar opciones entre fórmulas contrapuestas, cuando la concertación no se obtiene, con la prudente medición de los efectos que ellas pueden tener en una colectividad.

Tal espacio y paisaje difícilmente se van a encontrar en el seno de una Corte Constitucional, donde la mentalidad y los estilos imperantes, así como el discurso jurídico, transitan por otros caminos. En cierto modo, media allí un clima más profesional, universitario y académico en la tarea de hacer funcionar el derecho, que el propio de un Parlamento donde se sanciona ese derecho. Los jueces constitucionales, además, no tienen por qué sentirse comprometidos con los partidos e intereses sectoriales que, en cambio, anidan en los poderes Ejecutivo y Legislativo (y que es bueno que afloren y se contrapongan en el debate democrático). Antes bien, deben comportarse como sujetos imparciales e independientes, como por ejemplo exige el art. $8^{\circ}$ del Pacto de San José de Costa Rica.

Es por ello que el escenario judicial tampoco sea el más adecuado para generar normas, aunque ocasionalmente algunos tribunales, en ciertos países, hayan pergeñado proyectos de ley, en particular concernientes al quehacer judicial.

\section{c) El argumento funcional}

En este terreno, la pregunta estriba en determinar en qué medida la asunción de roles normativos por una corte constitucional puede perturbar el desarrollo de las tareas jurisdiccionales corrientes de tal órgano.

Por lo general, en el ámbito latinoamericano, las cortes y salas constitucionales tienen una cantidad de trabajo que no guarda relación con los recursos humanos y técnicos convenientes para asumirla. En otras palabras, resultan desbordadas por una catarata de procesos constitucionales de toda laya, concernientes tanto a la llamada "jurisdicción de la libertad" (protectora de los derechos personales), como a la "juris-

8 Nos hemos referido al tema en SAgüés, Néstor Pedro, (1978). Mundo jurídico y mundo político (Buenos Aires, Ed. Depalma), pp. 187-189. El Aquinate habla incluso del "arte de legislar" (de legislatione), como difícil empresa de compaginación normativa para alcanzar el bien común. 
dicción orgánica” (solución de conflictos de poderes y de controversias entre los órganos del Estado, por ejemplo).

En síntesis, pocos tribunales constitucionales han optado por una solución tan dura como la estadounidense, cuya Corte Suprema resuelve menos de cien causas por año. La mayoría se encuentra condenada a recibir, procesar y resolver miles de expedientes.

La cuestión es si ante tal panorama, es factible sumar a las funciones de una Corte Constitucional, la de actuar como legislador activo (aunque fuere suplente y precario), ante los supuestos de inconstitucionalidad por omisión. Naturalmente, la respuesta (desde un punto de vista exclusivamente cuantitativo), va a depender del número de procesos jurisdiccionales o parecidos a tales que debe decidir, y del número de causas donde tenga que actuar como legislador. Ese cálculo es decisivo para no asignarle a una corte constitucional misiones materialmente imposibles, que son en sí profundamente antisistémicas. Un tribunal o sala constitucional atiborrado de pleitos, y además, legislador, tiene el serio riesgo de incumplir ambos cometidos.

\section{BALANCE Y REPLANTEO}

Cuando a fines de los años sesenta el Tribunal Constitucional federal alemán asumió francamente el tema de la inconstitucionalidad por omisión en la producción de normas generales, alertó que los jueces, para remediarla, debían tener en cuenta tanto un claro mensaje constitucional incumplido, como el transcurso de un tiempo ya irrazonable sin que se lo obedeciera, y, por último, la posibilidad de que el Poder Judicial pudiese cubrir material y jurídicamente el vacío lagunoso, prescindiendo del legislador.?

Tales directrices conservan hoy vigencia. No es tarea simple atender jurisdiccionalmente la cobertura de esa inconstitucionalidad por omisión. Supóngase que la constitución encomienda al Poder Legislativo establecer un régimen de participación de los trabajadores en las ganancias de las empresas, con colaboración en su dirección y en el control de la producción, y que el Congreso permanezca renuente en esa obligación. ${ }^{10}$ Una magistratura constitucional que decidiese aquí poner punto final a la mora legislativa tendría frente a sí un trabajo hercúleo para elaborar soluciones individuales, y más todavía para redactar una norma general subsidiaria, en un asunto de por sí opinable y harto controvertido, con múltiples y distintas fórmulas de instrumentación, donde entran en juego diferentes índices de rentabilidad según las actividades y el tipo de establecimiento considerados, opuestos criterios políticos de redistribución de la riqueza, mediciones y resultados diversos acerca del impacto económico de las posibles cuotas y modos de repartir, etc.

9 Cfr. PIÑA, Rolando E. (1973). Cláusulas constitucionales programáticas (Buenos Aires, Ed. Astrea), pp. 72 y ss., Fernández RodríGuez, José Julio. (1998). La inconstitucionalidad por omisión (Madrid, Ed. Civitas), pp. 312 y ss.

10 El caso no es hipotético, sino que se presenta claramente en el art. 14 bis de la constitución nacional argentina, sancionado en este punto en 1957 y no reglamentado hasta la fecha, en tal cuestión. 
Una breve sinopsis histórica muestra que la jurisdicción constitucional no fue concebida inicialmente para reparar la inconstitucionalidad por omisión, sino solamente para inaplicar reglas inconstitucionales, en el caso concreto ("Marbury vs. Madison"). Que después, bajo las directrices de Hans Kelsen, pudo operar como legislador negativo, derogando las normas inconstitucionales. Y que más tarde, adoptó papeles de legislador positivo, impulsando la sanción de nuevas normas, v. gr. mediante las sentencias exhortativas. Finalmente, en una cuarta etapa, al atender la inconstitucionalidad por omisión en la producción de normas generales, cubrió vacíos lagunosos para el caso concreto, e impulsó la sanción de las normas ausentes, instando la actividad nomogenética del legislador ocioso, pautándole incluso ciertas directrices de contenido en la emisión de tales normas, y estableciendo reparaciones para el afectado por la mora legislativa genérica.

El fin de esta cuarta etapa parece alcanzar, según las soluciones de Chiapas y de Ecuador, una quinta alternativa: la gestión de un tribunal constitucional como legislador suplente y precario, sancionando bajo condición resolutoria la norma general ausente (esto es, hasta que quien debía elaborarla, lo haga efectivamente).

Si bien cabe destacar el ánimo de justicia y de ejecución real de la constitución que caracteriza a esta última posibilidad, en aras de otorgarle genuina eficacia y positiva vigencia de los derechos personales; y que la novedosa reprogramación que importa de la doctrina clásica de división de los poderes no la descalifica de por sí in limine, la problemática técnica, política y funcional que conlleva, y que hemos detallado anteriormente, no aconseja proyectarla como una solución deseable para todo sistema constitucional. Antes bien, lo mejor será evaluar con cautela las experiencias que ocurran en los estados que la han adoptado, antes que repetirla ya en otros. Para aquéllos, ciertamente, importa un desafío digno de una cuidadosa observación por parte del resto del derecho comparado.

Para el caso ecuatoriano, cabe alertar por último que la propia constitución deja en parte la instrumentación de la aptitud legisferante de su Corte Constitucional, a lo que establezca la ley, según se desprende del citado art. 436, inciso 10 (ver parágrafo 1). Ello deja abierta la posibilidad de enmarcar tal competencia dentro de ciertos parámetros, como los enunciados por el Tribunal Constitucional federal alemán, en torno a la factibilidad, en un caso concreto, de ejercer tal función prescindiendo absolutamente del legislador.

\section{BIBLIOGRAFÍA}

Fernández Rodríguez, José Julio. (1998). La inconstitucionalidad por omisión (Madrid, Ed. Civitas).

FernÁndez Rodríguez, José Julio. (2003). "La omisión legislativa en la constitución del Estado de Veracruz-Llave en el marco de la teoría general del dicho instituto”, en Ferrer Mac Gregor Eduardo (Coord.), Derecho Procesal Constitucional, 4 a ed., (México, Ed. Porrúa), t. IV. 
Ferrer Mac Gregor, Eduardo (Coord.), (2003) Derecho Procesal Constitucional, 4a ed., (México, Ed. Porrúa).

Muñoz Quesada, Hugo Alfonso y Haba, Enrique Pedro (1996). Elementos de técnica legislativa, (San José de Costa Rica, Ed. Prodel).

PIÑA, Rolando E. (1973). Cláusulas constitucionales programáticas, (Buenos Aires, Ed. Astrea).

RANGel HernÁNDEZ, Laura Maribel (2008). Inconstitucionalidad por omisión legislativa en México, (México D.F.). Tesis para optar por el grado de Maestro en Derecho Procesal Constitucional. Universidad Panamericana, pp. 157/8, versión policopiada.

SAGüés, Néstor Pedro (1978). Mundo jurídico y mundo político, (Buenos Aires, Ed. Depalma).

SAGüÉs, Néstor Pedro (2006). La interpretación judicial de la Constitución, $2^{\mathrm{a}}$ ed., (Buenos Aires, Ed. LexisNexis). 